\title{
Sleepless nights while our doctoral students are in the field: Supervisor reflections on ethical challenges
}

\author{
Kate Hutchings \\ Department of Employment Relations and Human Resources \\ Griffith Business School \\ Griffith University \\ Australia \\ E-mail: k.hutchings@griffith.edu.au \\ Snejina Michailova \\ The University of Auckland Business School \\ The University of Auckland \\ New Zealand \\ E-mail: s.michailova@auckland.ac.nz
}

\begin{abstract}
Prior studies have highlighted ethical challenges in researching in developing countries but have not explored the ethical issues for supervisors when their doctoral students undertake qualitative fieldwork in such contexts. Doctoral research in developing countries has the potential to provide valuable knowledge; yet, where data cannot be collected, important potential knowledge is lost. Moreover, where doctoral research does not follow ethical practice there is potential for damaged relations between organisations and universities which can impact student, supervisor and university reputation. Thus, doctoral students' supervisors have an essential role in providing training to ensure ethical and culturally appropriate research. We reflect on our experiences as supervisors of business doctoral students who collected original data in developing countries and underpin these reflections with our own extensive (international) management research in developing countries to discuss ethical challenges for supervisors. We offer insights and action guidelines for current and prospective students, supervisors, and universities.
\end{abstract}




\section{Introduction}

In this paper we offer a reflective account of the ethical challenges we have faced as supervisors of business doctoral students who undertook qualitative fieldwork (hereafter fieldwork) in developing countries. We detail our reflections through the stages of gaining access, collecting reliable data, and exiting the field. The guidelines we suggest are timely given the increasing business research being conducted in developing countries and the need to ensure research is ethically undertaken for strong organisational-university relations, university reputation, and organisational learning.

Over the last decade, there has been an increasing agenda for universities to more strongly engage with industry, government and not-for-profit organisations to provide knowledge, analysis and solutions for real-world problems (see de Wit-de Vries, Dolfsma, van der Windt, \& Gerkema, 2019). Developing countries are no exception - the focus there has, too, been on collaboration between universities and industry to leverage university knowledge, provide access to reliable data, enhance research and development, acquire and adopt knowledge, and enhance capabilities/skills development (Fischer et al., 2018). Doctoral students play an important role in undertaking initial forays into research. As many will segue into academic or other research-related careers, and those from developing countries often return from studying abroad to become leaders in their home developing country, they must develop the requisite skills to conduct research and generate knowledge. Doctoral research needs to be undertaken within strict ethics protocols developed by universities concerned for the ramifications if research goes awry and reflects national cultural values and organisational practice. When research does not follow ethics protocols, data may not be able to be utilised and results cannot be published. This can lead to potential loss of valuable knowledge and damaged relations with organisations and communities where data was collected (see WHO, 2009). Not following ethics protocols and respecting contextual requirements can result in 
burnt bridges and closed doors for future university-organisation research collaborations. This can have long-term flow-on effects for student, supervisor and university reputations. Thus, doctoral students' supervisors have an essential role in providing guidance and training to ensure students conduct ethical and culturally appropriate research.

We take developing countries to include less-developed countries within Africa, AsiaPacific, Central and Eastern Europe (CEE), Latin America, and the Middle East (World Population Review, 2019). Transition countries have economies evolving from being under government control to become a market economy in which companies_are not controlled by the government (Cambridge Dictionary, 2019). The former communist countries within CEE and in Asia and Latin America were classified as transition countries, although after a decade of reform, the CEE countries effectively joined the emerging countries (Meyer \& Peng, 2016), with the latter referring to developing countries with strong growth potential. We use the term 'developing countries' to cover developing, transition and emerging countries defined as still being at a lesser stage of industrial development. There is great diversity within the regions we examine (economic/extent of development, religious, ethnic), but also some commonalities (historical absence of law and/or formal institutions, necessitating more reliance on personal networks) (Michailova \& Worm, 2003; Peng \& Luo, 2000).

Several methodological challenges experienced in researching in developing countries have already been identified (see Devereux \& Hoddinott, 1992; Hoskisson et al., 2000). The resultant ethical challenges arise from but are not limited to difficulties in gaining access to organisations and participants (Binns, 2006), reliability of collected data (Binns, 2006; de Laine, 2000), and utilising western research ethics protocols (Smith, 2016). Many universities in developing countries have started to instigate research ethics procedures (see Mokgatla, 2018). In contrast, western universities and research institutions typically have well-established and elaborated ethics approval processes for conducting research (Wallace \& Sheldon, 2015). 
Defining 'western' is as fraught as defining 'eastern' or 'emerging' economies in respect to the increasing diversity within and across countries within these categories, resulting from, among others, high levels of migration and increased multiculturalism. Definitions of the west form part of the discussion about the north-south divide and post-colonialism. Culturally, the west refers to countries shaped by western Christianity with similar cultural and ethical values; politically, it is typically associated with the Cold War West of capitalist countries in contrast to communist states; economically, it encompasses countries with high gross domestic product (and often countries they colonised) (World Population Review, 2021). Herein we use the term 'western universities' to refer to universities operating within Australia, New Zealand, North America, North, South and West Europe (i.e the cultural definition referred to above but including some of the major Anglo economies that emerged from colonisation).

Acknowledging there are ethical challenges when conducting fieldwork in any context, we focus on doctoral students who undertake a thesis over three to four years involving original, qualitative, primary data collection in developing countries. We intend to demonstrate and discuss the ethical challenges for supervisors of doctoral students researching in developing countries. Such challenges arise from students being geographically distant from their supervisor based in a western country, combined with developing countries often not having the same research processes/ethics protocols. These two factors, we argue, intensify the ethical challenges at play. We explain how access to the field, securing data, and maintaining confidentiality are more challenging in developing countries than in other contexts. The issues result from a range of factors, including, in some countries, military dictatorships and strong government or police monitoring of research, and high levels of violent crime, as well as cultural values requiring reciprocity and maintaining contact following research.

Post-colonialism is manifest with exploitation of developing countries for research (see, for instance, Hawkins \& Emanuel, 2008). We acknowledge post-colonialism (the legacy of 
colonialism) and the potential impacts of neo-colonialism (indirect influence) when researchers (including doctoral students) from western universities conduct fieldwork in developing countries. Cultural imperialism may occur when researchers follow accepted practice from western institutions without consideration being given to norms and values associated with, and attitudes towards, research in the developed country/ies, and they do not recognise the need to move away from a western 'expert' stance to be culturally sensitive to local context (Crossley \& Vulliamy, 1997). Widdows (2007, p. 315) argues that "even in cases where attempts to be more representative are being made the danger is that Western ethics is simply regarded as a 'base' which is 'added to' [...] and the critiques of this dominant framework and the insights of non-Western and alternative forms of Western ethics continue to be peripheral". Noting that the institutionalisation of research ethics is a relatively recent historical phenomenon, Sabati (2019) points out that research ethics is understood within the bounds of specific research projects. This implies that it does not consider sufficiently the complexity of the broad social and political contexts that shape both where research takes place and the institutions through which researchers do their work. Thus, it is crucial that researchers take seriously the responsibility to critique how research is conducted and the (sometimes un)suitability of largely Western notions of ethics for use across multiple cultural and institutional contexts. Moreover, referring to 'colonial unknowing', Sabati (2019) highlights that research ethics occurs in a context where knowledge production and academic institutions are complicit in producing and upholding power relations and presenting their own understanding of what is ethical research. Sabati (2019) further argues that researchers and institutions need to take seriously anti-colonial 'answerability' towards communities and contexts. A thorough examination of the power dynamics when scholars from western/global north countries and institutions undertake research in developing countries/the global south and research according to their understandings of ethics in research is beyond the scope of this 
paper; however, we highlight the importance of these issues and the need for them to be considered when supervising doctoral researchers.

We recognise there has also been exploitation of Indigenous people in developed (and developing) countries in research (Smith, 2013). Such neo-colonialism may occur where Indigenous peoples are not involved in research that affects and is of value for them; Indigenous peoples may also hold negative views of research due to the legacy of colonialism and how they were used in research (see Bishop, 2011). Thus, increasingly, there is an emphasis within the literature on the value of indigenous research in international and cross-cultural management (Jackson, 2013). There has been a substantial increase in the number of doctoral students researching in developing countries, which applies especially to business and management (Robinson, 2018). Yet, to-date there have been relatively few articles written by doctoral students reflecting on their experiences with ethics of researching in developing countries (examples include Azungah, 2019; Binns, 2006; Gokah, 2006; Howes et al., 2006; Liong, 2015). Even when researching within their country of origin, they face logistical, emotional and ethical issues (Howes et al., 2006).

There has been a stream of publications about teaching business ethics to university students (e.g. de los Reyes, Kim \& Weaver, 2016; Nhung, Hendy, Basuray \& Smith, 2017). However, there is limited time available for doctoral students to acquire ethical sensibility aligning with knowledge of local cultural norms in geographically dispersed fieldwork sites (Smith, 2016). Though some countries have established guidelines for doctoral supervision practice and supervisor responsibilities, our experience is these do not provide a detailed explanation to support students who conduct fieldwork, in general, or in developing countries, in particular. de Laine (2000) discussed the role of academic gatekeepers and the power relationship of supervisors over students as presenting ethical dilemmas in research. Wallace and Sheldon (2015) analysed perceived low-risk ethics applications from business doctoral 
students against the principles of established research ethics guidelines. However, we have not yet seen researchers discuss (in writing) the difficulties academic supervisors encounter when their doctoral students undertake fieldwork in developing countries. We note that such discussions do take place in informal conversations.

Given the ethical issues confronting researching in developing countries - from entering the field through fieldwork to exiting the field - we decided it was salient to address this gap in research by specifically articulating, based on our own experiences, academics' ethical challenges when supervising doctoral students who research in developing countries. The research question we pose is: What are the ethical challenges faced and decisions made when supervising business doctoral students who undertake fieldwork in developing countries, and how should supervisors train doctoral students to ensure they follow culturally appropriate ethics protocols?

The following section outlines our position as doctoral supervisors and explains why we wrote this paper. We then offer a brief overview of the literature about ethical issues arising from research challenges in developing countries. The subsequent section articulates our reflections and presents action guidelines. The final section provides concluding remarks and outlines limitations and issues for future research and implications of our analysis.

\section{Our position as doctoral supervisors and the value of reflexivity}

The increasing economic and strategic significance of developing countries has led to increased management and business-related research conducted in these countries. While some doctoral students studying developing countries have country-of-origin/residence in the developed world, many belong to the increasing cohort of students from developing countries studying in western countries (Robinson, 2018). 
We have long-standing experience supervising doctoral students who have conducted fieldwork in developing countries and undertake such research ourselves. We consciously and deliberately chose to reflect on our own experiences as doctoral supervisors when our students conduct fieldwork away from the safe environment where we meet with them regularly and have our hand on the pulse of their doctoral work. We argue supervisors encounter ethical challenges without being directly involved in the research because: the supervisor is accountable to the university ethics committee; the supervisor has the responsibility to oversee the student's research; and the difficulties increase when there are fewer opportunities for communicating with the student.

Reflexivity implies "thoughtful self-awareness" (Finlay, 2002, p. 532), “deliberate selfscrutiny" (Hellawell, 2006, p. 483), and explicit interrogation of issues we deal with and processes we go through while in a doctoral supervisory role. In such a framework, subjectivity is not a liability or a feature to try to escape from; quite the contrary - "[t]hrough the use of reflexivity, subjectivity in research can be transformed from a problem to an opportunity" (Finlay, 2002, p. 531). Hence, we openly disclose our role as active participants in the supervision process in guiding our doctoral students and being responsible for maintaining their research integrity ${ }^{1}$. We draw inspiration from Anteby's (2013) argument that although scholars have generally been discouraged from telling their stories in writing in respect to their personal involvement in a field, holding both distance and involvement is legitimate and important. Being a scholar involves being part of the story. Moreover, though Dimov and Pistrui (2020) noted for [social] scientists, there has been an emphasis on a detached, third-person perspective, they referred to Searle, who suggests a first-person ontology is not reducible to a third-person

\footnotetext{
${ }^{1}$ Within many western universities it is the doctoral supervisor who must be named as the first chief investigator on the doctoral research ethics application and is responsible for ensuring that the doctoral student follows the required ethical protocols. Moreover, the supervisor will ultimately be held responsible if anything untoward occurs or if there are complaints from research participants (even when the research is conducted by the student in another country and out of contact of the supervisor).
} 
ontology as an experience independent of any other agent. In telling our story reflexively to explain ethical challenges faced by doctoral supervisors, we deliberately crush the taboo of personal involvement and emphasise the value of the first-person experience for providing guiding insights for others' journeys.

The first author is Australian (of European heritage) and completed a $\mathrm{PhD}$ in an Australian university involving fieldwork in, and examination of, human resource management in international businesses in developed and developing countries in Asia. The second author is of European heritage and completed a PhD in a European country involving fieldwork in, and examination of, business in a CEE country. We have amassed a combined research experience across various sub-disciplines in management and international business, amounting to well over 250 refereed publications, many of which focus on developing countries. Collectively we have worked and researched across many countries in Asia-Pacific, Europe, Middle East, and North America. As we have primarily worked in western institutions, we have followed the ethical traditions of those countries. This implies we have dealt continuously with our own "ethically important moments" (Guillemin \& Gillam, 2004) when conducting fieldwork in developing countries. By this, we understand both the protocols of western universities' ethics requirements and the different ways of researching developing countries. We find ourselves reconciling the two when we conduct our research and advise doctoral students.

We have extensive experience supervising doctoral students and advising junior researchers about researching in developing countries. Collectively we have supervised 23 doctoral students undertaking theses over several years, including 16 who did their research in nine developing countries, namely, China, Ghana, Indonesia, Jordan, Malaysia, Russia, Sri Lanka, Thailand, and Vietnam. All students were citizens of those countries or had extensive prior experience working in the country. Their intent in undertaking their research was to build 
knowledge of the country that would be economically and/or socially beneficial; thus, they did not undertake fieldwork from an explicit or implicit point of exploitation.

Understanding how supervisors make sense of their world is important, but advice for them is scant (Wright, Murray \& Geale, 2007). Working from the premise that supervision is socially constructed by supervisors, doctoral students, and other academic community members and based on lived experiences, these authors established five supervision categories - Quality Assurer, Supportive Guide, Researcher Trainer, Mentor, and Knowledge Enthusiast. We do not see ourselves as fitting into a single category; instead, we adjust our supervision practice to each students' needs, reflecting their prior learning and experience and their cultural values about the supervisor role. In some instances, we adopted a Knowledge Enthusiast role in taking a student on a knowledge journey. In some cases, we had to limit our role to Quality Assurer or Supportive Guide. Most of the time, we work as Researcher Trainers to student apprentices, or subject to their cultural comfort of stepping out of teacher as holding all knowledge, as Mentors. Though we acknowledge we have a degree of power to influence a student's research direction, our starting point, in our practice and in this paper, is a concern our students should follow the ethical protocols of the universities where they are enrolled and undertake culturally appropriate research.

Here we position our reflections against how we view our role as supervisors, generally, and our particular ethical challenges in supervising our doctoral students who conduct fieldwork in developing countries. We used a qualitative narrative approach of reflexivity, a legitimate and validated qualitative research procedure (Mortari, 2015). We interleaved prior research examining ethical challenges in researching in developing countries, reflecting on the ethical challenges we encountered as supervisors when our students went through the three phases of fieldwork. We deliberately chose to examine the different fieldwork phases as this aligns with literature on ethics in doing research, but also because we had experienced ethical 
challenges whilst our students were involved in these phases - before fieldwork (gaining ethics approval), during fieldwork (gaining access to organisations/participants, gathering usable data, ensuring safety) and after fieldwork (reporting and publishing research). The process of deciding which reflections to include entailed multiple conversations about ethical challenges we had experienced individually and collectively to determine which critical incidents (see Shapira-Lishchinsky, 2011) in our supervision were common and/or would most insightful for readers. Though such critical incidents may have been quite dramatic in some cases, in other cases they just gave us pause to reflect on the extent to which we needed to intervene to provide ethical quality assurance, guidance, or training for our students. We also considered which critical incidents allowed us to reflect on, and scrutinise, our own supervision practice. Through this iterative process, we arrived at a few important supervisory ethical challenges to explore within the paper. We emphasise that we do not consider these to constitute an exhaustive or complete list.

\section{Ethical issues arising from challenges in conducting fieldwork in developing countries:}

\section{A brief overview of existing literature}

Multiple issues exist when undertaking business research in organisations (Wallace \& Sheldon, 2015); thus, it is essential to understand the context in which research fieldwork occurs. The accuracy of gathered data may be compromised if methodological contextualisation is not considered carefully (Michailova, 2004). Qualitative fieldwork, with its typical close interaction with research participants, can be inherently problematic as this closeness raises challenges for anonymity and confidentiality; accordingly, fieldwork is intrinsically associated with ethical problems (de Laine, 2000), especially in developing countries. Further, strict adherence to bureaucratic guidelines and codes does not mean a researcher is necessarily conducting ethical research as ethical codes do not encompass all ethics aspects they are 
designed to guide (Guillemin \& Gillam, 2004; Liong, 2015; Stening \& Skubik, 2007). Therefore, ethical requirements may be problematic for researchers - during fieldwork "[o]n one hand, researchers must comply with their ethical obligations by 'doing things right', but on the other hand, researchers can feel compelled morally to 'do the right thing' to protect participants from harm" (Stringer \& Simmons, 2015, p. 255). Such morality is essential in recognising that while it may be possible to determine many empirical data collection procedures before entering the field, this is inherently difficult because of the fluidity of qualitative research (Liong, 2015). That is, qualitative research allows for and often necessitates changing approaches during data collection, but this needs to reflect ethical considerations.

As noted, there has been limited research examining doctoral students' perspectives of challenges in fieldwork in developing countries. Amongst the research that has been published are studies examining denial of access, physical and psychological issues in accessing organisations, and negotiating and building relationships of trust with gatekeepers (Azungah, 2019); reflections on planning and logistics of fieldwork (Binns, 2006); physical risk and risk to research data, and naivety in doing fieldwork (Gokah, 2006); and ethical issues in positionality in ethnographic research (Liong, 2016).

The following section presents a brief overview of doctoral and other researchers' publications examining ethical issues that arise from challenges in conducting fieldwork in developing countries.

\section{Difficulties in gaining access to organisations and research participants}

Although conducting research is time-consuming in all contexts, in countries with no strong research tradition (with developing countries typically belonging to this category), it often takes considerably longer to gain access to the field. For first-timers (like doctoral researchers), 
gaining access can lead to frustration, lost time, travel expenses and, sometimes, a need to change research plans (Gokah, 2006). Binns (2006) cautioned researchers not to rush too quickly into the field, but first to spend time visiting government offices, non-government organisations and universities and gather documentary information that may not be available outside the country. Moreover, time often needs to be invested in building trust before engaging in the more instrumental parts of the work.

It can be challenging to obtain access to organisations in Africa and the Middle East, given formal policies preventing research or long delays in response (Lages, Pfajfar, \& Shoham, 2015). This also occurs in parts of Asia, CEE and Latin America. Further, in contexts with (former) authoritative political regimes and no strong empirical business research traditions, organisations and individuals are sceptical of research (Hutchings \& Michailova, 2006). In some Latin American countries, like Cuba, there are various restrictions on locations and access (Bell, 2013). Thus, researchers face challenges in gaining access, naturally raising ethical issues while maintaining academic independence/distance.

In Africa, specialised intermediaries play a significant role in fieldwork (George, Corbishley, Khayesi, Haas, \& Tihanyi, 2016). In addition to university ethics documentation, one needs a letter of introduction from a government department/body. Potential participants will want to contact them to verify information (Azungah, 2019). Even when such letters are obtained, gatekeepers often block access as they fear the researcher seeking to uncover unacceptable practices. In parts of Africa, gaining access often requires researchers to have escorts who may take over responsibility for lining up potential participants and scheduling meetings without thinking about the researcher's financial or time constraints (Gokah, 2006).

Reliable databases, registers or archives typically provide important preliminary information a researcher needs when preparing to undertake fieldwork. In CEE these are not easily accessible, and personal networks may be the only way to get to data (Michailova, 2004). 
In some countries, such as Vietnam, research involves a lengthy process of working through bureaucracies (Waibel \& Ehlert, 2013), and in many contexts, facilitators are needed to assist access to individual participants after organisational access has been achieved (Binns, 2006).

\section{Challenges in gathering reliable data}

In developing countries, research participants often do not trust ethics documentation; fear, lack of trust and overly positive responses often dominate. Potential research participants may not trust the assurances of ethics committees and researchers that the information they provide will remain confidential (Baez, 2002). This especially prevails in cultures where people may have been denounced and reported to government officials by their colleagues, neighbours, or friends for purportedly not following the political regime's dictates. Even when such countries have transformed into democracies, the legacy remains in that people continue to fear sharing their views (Michailova \& Hutchings, 2006) or, where they do participate, they provide only positive assessments as they fear repercussions from management or other authorities.

Low participation rates, lack of suitable participants, and insufficient data quality are significant data collection issues in Africa and the Middle East (Lages, Pfajfar, \& Shoham, 2015). Gathering data in rural areas can be especially difficult as often people do not have sufficient literacy to be research participants. Participants in the Arab Middle East tend to offer socially desirable responses, and they often tend to present themselves the way they think they should appear to others (Hawamdeh \& Raigangar, 2014). These practices occur in other developing countries with collectivist and high-power distance cultures, such as China and Southeast Asia. In communist countries (China, Vietnam) and former communist countries (CEE), the suspicion people may hold about the research process means many will be reluctant to have their responses recorded (Michailova, 2004; Nojonen, 2004). 
Considerable time may need to be spent with participants in the field before the actual data collection begins. Long conversations and coffee breaks are important in many developing country cultures, given the emphasis on respecting them as social occasions (Howes et al., 2006). In the Arab Middle East, relationships and trust need to be built, involving hospitality; thus, an interview may last three hours over shared refreshments (Hawamdeh \& Raigangar, 2014). In China and CEE, reciprocity of favours is essential; those who do not return favours are viewed as untrustworthy (Berger, Herstein, Silbiger, \& Barnes, 2017). In Indonesia, interviews are more successful if the participant finds them relaxed and informal and they often request a colleague/friend/relative to attend the interview with them (Nguitragool, 2014).

Informed consent and voluntary participation pose additional challenges. Within patriarchal or matriarchal societies, it may be essential for non-research participants to give consent for others to participate. In some African cultures, consent relates to marriage and motherhood (which may be younger than 18) (Amerson \& Strang, 2015). In some cultures, a male must consent for a female to participate in research (Amerson \& Strang, 2015), and senior members of communities may need to give consent for others (Azungah, 2019). Complying with ethics requirements necessitates participants to provide voluntary informed consent in writing, but in cultures with a strong oral tradition (e.g. Africa, Asia, CEE, Latin America, and the Middle East), verbal consent is valued (Amerson \& Strang, 2015). Obtaining written consent from Arab participants can be difficult as asking a person to sign a 'contract' is insulting (Hawamdeh \& Raigangar, 2014).

In some developing countries, research participation may not be voluntary due to hierarchical roles, expectations and organisational and/or national cultural features. Some potential participants may feel obliged because of respect for authority or because a manager requests/orders participation (Wallace \& Sheldon, 2015). In the Arab Middle East, some participants will answer all questions, including ones that make them uncomfortable, due to 
courtesy (Hawamdeh \& Raigangar, 2014). In many developing countries, participants are unlikely to withdraw after the research commences, although they may wish to, because of respect for those perceived to be in a position of authority.

\section{Issues associated with exiting fieldwork}

Completing fieldwork is not always about closure; it can also be about new beginnings (Michailova et al., 2014). Often exiting the field is associated with maintaining relationships with research assistants/translators and research participants. The participant-researcher relationship does not necessarily end once data are collected (Morrison, Gregory, \& Thibodeau, 2012). An essential part of researching in the Arab Middle East, for instance, is responding to telephone calls at any time which could entail requests for favours or dinner invitations (Hawamdeh \& Raigangar, 2014) as consistent with the collectivist, hospitable and relationships-before-business culture. Though time-consuming for researchers, this relationship nurturing post-data collection is also critical in Africa, parts of Asia, Latin America and CEE.

In developing countries, there are additional issues that need to be dealt with personally when exiting fieldwork. Some of them relate to advising participants about how they may contact the researcher/s and demonstrating appreciation for participants' involvement. Examples of such appreciation are mentioned by Azungah (2019), who gave thank you cards to participants in Africa, and Binns (2006), who offered laminated copies of photographs taken during an earlier research project in Africa. Such practices can be important in providing participants with a positive view of the research experience.

Across all stages of fieldwork: research risks, conflicts of interest, and conflicts of values 
Research risks may occur throughout all stages of the research process - from before entering the field while negotiating access, while in the field, and post-fieldwork. Although ethics applications may require researchers to identify potential risks to participants, they do not usually directly enquire about the risks to researchers (with exceptions of university approval being required for researchers to do fieldwork in countries identified by the university's national government as posing security/safety risks).

Risks to researchers' safety (harassment/bullying/intimidation, sexual harassment, theft/armed robbery, etc.) and health (illness from food poisoning or water contamination, contracting a disease or illness) are underreported (Sampson \& Thomas, 2003). Azungah (2019) described how after a day of data collection in Ghana, when flooding occurred and unable to catch a taxi, he needed to walk four miles through a forest to reach home; all the while concerned about theft by armed robbers given he carried a laptop and data recorder containing confidential interview data. Stringer and Simmons (2015) observed that fieldwork, despite careful research design, exposes researchers to risk as they may face threats or physical harm resulting from what they have found or intended to publish/publicise. They further argued there had been limited knowledge of researchers' risks due to self-censorship and avoidance in tackling sensitive or taboo subjects. Although researchers may seek information about potential danger and risky situations to protect themselves better, this may not take away anxiety (Gokah, 2006).

Moreover, conflicts of interest and conflicts of values can occur across all stages of fieldwork. Fieldwork can become particularly sensitive when it crosses the boundaries of conventional and sensitive topics, public and private spaces, overt and covert spaces, field notes to texts, and when there is overlap in roles and relationships (De Laine, 2000). There can be conflicts of interest in Latin America as many researchers work in civil service departments with hierarchical systems and researchers may be seen as 'closed communities' (Litewka, 
2011). Researchers who engage with participants on an emotional level (including the potential development of friendships) and have access to participant confidences and private physical locations may face a range of practical and emotional challenges (de Laine, 2000, Michailova et al., 2014). This is especially so when information should be reported to authorities but the researcher has a moral obligation to maintain trust and confidentiality. There can be additional ethical challenges when conducting participant observation where the researcher is not in accord with an organisation's thinking and there is a conflict with their own values. For instance, Liong (2015, p. 65), researching in Hong Kong, observed: "I did not agree with the discussion group participants and always felt the urge to argue with [...] their patriarchal comments and thoughts. However, expressing my views to the group members in the meetings was inappropriate". de Laine (2000) argued the researcher has a responsibility to follow codes of practice and draw on their values in making a decision that is most 'right'.

Table 1 summarises shared characteristics of developing countries that present ethical challenges that differ from western countries. While we do not suggest that these characteristics will apply universally to every developing country or every individual in a country, they are common to countries that do not have strong traditions of research or research ethics processes.

[Insert Table 1 here]

Building on the challenges in researching in developing countries we presented, we now draw on our experiences to discuss ethical challenges and decisions that may surface in supervising doctoral students who conduct fieldwork in developing countries.

\section{Reflections on ethical challenges and decisions facing doctoral supervisors}


In Figure 1 we summarise key ethical challenges (as detailed in the prior literature) and present issues related to the four key points at which ethical challenges for supervisors arise, namely: assisting students in preparing ethics applications before entering the field; limited supervisor help and/or control when students need to make decisions in the field; supervisors' limited control over issues of security during students' fieldwork; and supervisors' inability to influence how students present research after exiting the field. We discuss these issues as they occur before, during, and after fieldwork.

[Insert Figure 1 here]

\section{Assisting doctoral students to prepare ethics applications before commencing fieldwork}

Before entering the field, doctoral students work with their supervisor/s to prepare documents to attain ethical approval/clearance. The ethics approval process focuses on minimising participant risk/harm and moral requirements (Stringer \& Simmons, 2015). However, they are typically framed in a western ethnocentric model of how people (are expected to) behave. So, already at this stage of the research process, we have faced an ethical challenge as supervisors. We need to ensure the application meets ethics protocols and the student can begin data collection. Yet, having undertaken extensive research in developing countries ourselves, we know they will experience difficulties in gaining access and ensuring informed and voluntary consent.

Nonetheless, in training students as future researchers, we have asked them to proceed as required and know that they will likely need to modify some of the procedures they have outlined in their applications when they are in the field. We know the data collection will take longer; potential research organisations and participants may agree to participate and then decline (Azungah, 2019). Some potential participants will be offended when asked to sign a 
consent form (Hawamdeh \& Raigangar, 2014). We expect the students' ability to gain voluntary participation will be affected by cultural values. That is, some respondents will be guarded in what they say, others will reveal more than they would have liked and seek to retract, some will require others to speak for them (Jentsch \& Pilley, 2003), and many will not want to be recorded or observed (Michailova, 2004; Nojonen, 2004).

In supporting doctoral students to research in their country of choice, which may be under-researched and provide a novel research site, we have openly discussed with them the challenges they may face in gaining access and collecting usable data, the ethical difficulties they may experience in the field, and the need to make some alternate arrangements without our input while being conscious of following approved (western) university ethics protocols. In setting expectations for students, we have a critical role in training students to understand how to undertake research appropriately. As part of this dialogue, where a student is a citizen of the country in which they will undertake fieldwork, as supervisors, we have gained insight from some doctoral students about national cultural practices affecting the research process and have used this learning to inform our supervision of subsequent students. Thus, we suggest that, in preparing ethics applications, supervisors should partner with their doctoral students to provide detailed information to the ethics committee explaining the specificities of researching in a particular country. Alternative approaches (a Plan B and potentially Plan C) that could be enacted to gather data within a culturally acceptable and ethically sound process should be presented. We have learnt from our students it may be necessary to negotiate using verbal instead of written consent or have a local contact read the researcher's interview questions and take interview notes in their presence.

Human research ethics committees are responsible for ensuring doctoral students follow strict protocols to minimise potential harm in the research process. By necessity, this means they tend to follow ethnocentric norms. To ensure greater ethical sensitivity in how 
research needs to be conducted in developing countries, there must be advice about how to undertake ethical and contextually sensitive research. Yet, not all responsibility should rest with the supervisor. We suggest conducting workshops/seminars within departments/disciplines at which advice and reflection on practice are discussed by academics, post-doctoral fellows, and experienced doctoral students. Such workshops might also include participation by ethics committees' members to ensure alignment of expectations and practices. Moreover, providing some of the doctoral supervision in a group/cohort format can help establish a community of interest for sharing approaches to undertaking ethical and culturally sensitive research informing other students' and supervisors' practice. We, therefore, suggest the following action guidelines:

Action guideline 1: Supervisors should educate and train doctoral students to prepare ethics applications that explain and justify how the research will be conducted in a particular developing country context and how this is likely to differ from established norms and practices in a western research setting.

Action guideline 2: University ethics committees should support and provide ethics clearance for well-justified alternative approaches to data collection that ensure research integrity outside an ethnocentric approach to fieldwork.

\section{Limited supervisor help/influence when doctoral students need to make decisions in the}

\section{field}

In contrast to the developed world in which access to organisations is typically agreed by managers/employees and then the researcher proceeds to undertake the scheduled research, in developing countries access often needs to be negotiated (and re-negotiated multiple times) once in the field. This often necessitates spending a much longer time in the field, meaning the student manages the data collection with the supervisor/s having limited or no influence over 
the process. Students may have limited contact with their supervisor/s during fieldwork because of logistical issues such as unreliable/limited/non-existent internet or telephone access in some parts of some developing countries (see Bell, 2013). In our experience, time in the field can be incredibly stressful for the student concerned about ensuring they collect sufficient data. As supervisors, we have also found this stressful when we worry about whether our students follow ethics protocols or make required adjustments that follow ethical practice.

In examining choices in grounded theory in a management/organisational research context, Alammar et al. (2019) advocated doctoral students should make their own choices in research. de Laine (2000) cautioned students may have general knowledge of ethics issues in research but find themselves challenged when things do not follow the plan outlined in the ethics protocol. The student-supervisor relationship itself may blunt the student making their own ethical and moral choices. We agree this may occur in some instances, but we generally advocate students make choices under supervisor guidance. We have experienced situations in which, once in the field, a student essentially needed to follow their plan and rely mainly on their own resources when contact with us was limited. This raised concerns about whether the student has sufficient knowledge to make appropriate decisions about alternative strategies and whether they would fit the approved ethics protocols. In such situations, we have had overarching unease about the potential effect on research participants if there is insufficient informed consent or anonymity and flow-on effects of damaged relations with organisations and reputation for our student, us, and the university.

Even when our students have stayed in contact, it may have been on an irregular basis, especially when researching in a remote area and needing to travel back into a town/city to email/phone. Yet, the difficulty of making contact with the supervisor/s may not be the only reason why students work independently during fieldwork. Some students who may have had regular meetings with, and advice from, us while working on the thesis before fieldwork but 
have expressed the data collection is the 'real' research that is their own. Students are trained in a research doctorate for approximately four years (depending upon the country of enrollment and their progress), but when confronted with difficulties in the field, a student from any country may instinctively revert to previous practices instead of strictly following ethics protocols of their enrolling university.

Students' cultural values can have considerable influence during fieldwork. For instance, students from high power distance cultures do not want to disagree with people in authority (Wallace \& Sheldon, 2015) i.e. the supervisor/s. This may affect the development of critical thinking and the ability to adjust research methods in the field but may also mean the student follows a not entirely practicable ethics protocol to the letter. This may result in the inability to collect reliable data and a lost opportunity for contributing to knowledge. A cultural emphasis on harmony and not wanting to cause conflict (see Liong, 2015) may also mean a student does not think about collecting data using a different approach. In our experience, students from high power distance cultures think of the supervisor as having all the knowledge and influence. Thus, part of our role has been encouraging students to partner with us. We have learnt from them about what aspects of data collection may need to be negotiated for their country of research (and necessitate a variation to the original ethics approval).

Students may think their supervisors are too busy and want to focus on their own research while doing fieldwork and may be reluctant to 'bother' the supervisor. This may result in students making their own decisions to change the agreed data collection procedures and engage in unethical practices. We have also seen students turn to other students for advice. While we have generally encouraged students to develop a community of practice with other doctoral students to discuss their studies, other students do not have the research experience of the supervisor/s and may give unsuitable advice. We have felt concerned when we are not overseeing the research in the field; our students may have made less than optimal choices if 
they sought advice from other students or made their own decisions without discussing alternate scenarios with us.

In our research, and that of our doctoral students, we have found that, in developing countries, secretaries/executive assistants/personal assistants usually act as gatekeepers who maintain manager emails and filter requests. This makes it difficult for doctoral students to establish even an initial contact with the appropriate person. When a student experiences repeated rejections from organisations in gaining access, they worry they may not be able to finish their doctorate and think it is too difficult to strictly follow approved ethics protocols. Consequently, on occasion, students have queried whether it would be suitable to ask local contacts to collect data for them or ask their families and/or friends to be research participants. Though we acknowledge that in the student-supervisor relationship, we potentially have power and influence, some of this influence is reduced when students are in the field, and we see our role as supervisors as one of guidance and training; not of merely providing instructions to follow. We have gained insights from our students about working through intermediaries. The student's thesis may benefit from drawing on the advantages of insider access and outsider objectivity (Wright et al., 2018). Still, as we are also accountable for the research, we have needed to reinforce expectations to ensure participant safety and that the student undertakes the data collection. Though it is pretty common for researchers to collect data by going to their contacts and snowballing from them, we have explained to students the importance of collecting their data as part of the doctoral training process of designing and conducting an independent research project.

Even if our students ethically and successfully gain access to organisations and participants, we have worried that they may not have the required skills to gather reliable data. Students may face difficulties when it comes to conducting interviews and focus groups. For instance, we have seen situations where a student may not sufficiently refine the interview 
questions or probe participants to gain the required information and return to the university with insufficient data for analysis. This means the time and finances spent on data collection are not optimised and a return visit may be required to engage in additional fieldwork. Conversely, a student may lead a participant too closely by overly explaining what the questions mean and what they expect in the participants' responses. This is likely to happen in collectivist cultures where the student may identify with the participant as part of their group or in high power distance cultures where the participant would expect the researcher to advise them on required answers. We have had situations where a student had a similar experience to the participants and spent too much time in interviews or focus groups talking about their own knowledge of the topic area; this required us to work with the student to develop more distance from the research. Once in the field, students may adapt the questions previously agreed with the supervisor/s and make a participant uncomfortable or offended, thus causing harm to participants and resulting in a lack of ethical process (Agee, 2009). Though universities may provide generalist, cross-disciplinary information sessions on data collection practices, supervisors are disciplinary experts. We have helped our research students develop skills in facilitating qualitative data collection with, for instance, mock interviews. These insights lead us to propose:

Action guideline 3: Supervisors should provide tailored training to and guide doctoral students to ethically conduct fieldwork that aligns with the developing country's specificities and the university's ethics requirements in the developed country.

Given doctoral students are novice researchers, we have aimed to maintain regular contact with them throughout fieldwork. We have experienced challenges in doing this, particularly in remote locations, but believe time should be built into the fieldwork to allow for the training students require. For instance, a student researching in a remote area may need to build in one day per week/fortnight to travel to a location with reliable internet access to contact 
their supervisor/s via Skype, Zoom, or email. In our experience, this has been manageable when the meeting/correspondence time is scheduled in advance (and we were available out of usual office hours to allow for geographic time differences). This leads us to:

Action guideline 4: Supervisors should require doctoral students researching in developing countries to arrange regular contact with them to discuss potential ethical challenges they may encounter during fieldwork.

At many universities, doctoral students will be required to attend a research integrity session/module. Given students often enter research programmes without prior knowledge of research ethics and many intend to pursue research careers, there needs to be more guidance from universities and supervisors about ethical research practice. Wallace and Sheldon (2015) highlighted while researchers often must report to ethics committees when their research concludes, this is concerned with performative matters. The authors advocated for candid reporting back to ethics offices, asking applicants about any ethical issues that emerged and how those were addressed. We concur with this suggestion and argue it could also be beneficial to provide these reports in a collated, de-identified version to use as a how-to guide for other researchers/doctoral students. This could be supplemented by face-to-face training sessions or online modules specifically devoted to discussing ethical challenges in researching in developing countries. This leads us to propose:

Action guideline 5: Universities should provide tailored training courses, modules and/or guides advising researchers of ethical challenges in, and possible solutions for, researching in developing countries. Reporting back to ethics committees/offices should be integrated into ethics (approval) processes that consider contextual specificities.

\section{Supervisors' limited control over issues of safety when doctoral students are in the field}


When our students are in the field, we have been concerned that they may face a range of potential data security risks and safety risks to themselves and their research participants. There is the possibility of compromised confidentiality of responses when doctoral students are in the field and do not have access to secure facilities to store data. In many universities, the supervisor/s is responsible for the secure storage of data. While we, as supervisors, may keep the data in locked cabinets for five or more years after data collection, it has concerned us we do not have control over data storage while our students are in the field, particularly when collecting data in a remote area for weeks and sometimes months. Some of our students did not have internet access to store data in cloud-based tools and their only way of storing data was on a notebook computer and external hard drive. This not only meant data could be lost due to lack of back-ups (requiring further time to re-collect data), but the confidentiality of data is also at risk if the computer/drive is stolen. Moreover, in some developing countries, government officials may monitor research activities and doctoral students may be at risk of having their data confiscated. For instance, when leaving the country, customs/immigration officials may confiscate student computers or paper records/documents collected in the field may be intercepted through postal services and examined to investigate the student's research. So, we have been concerned about the risk our students may face and that confidential data may have been lost; which may also mean damaged relations with organisations if data becomes available. This can have long-term consequences for university-organisational collaboration and student, supervisor and university reputation. Thus, procedures need to be established by supervisors and students to ensure data can be regularly backed up and confidential information deleted in case of loss. Following these arguments, we put forward:

Action guideline 6: Throughout fieldwork, doctoral students should save data to cloud-based storage applications and/or send the data to the supervisor/s (in the form of passwordprotected documents) for secure storage. 
Stringer and Simmons (2015) noted risk in the form of potential harm to researchers and their research assistants and translators. Although in some developing countries, all visitors are at potential risk of random theft and assault where such activities are prevalent (Azungah, 2019; Gokah, 2006), as supervisors, we worry this risk may be heightened when students are undertaking ethnographic research and are living the research daily or when the research may be considered unacceptable by local authorities. Business research in developing countries is indeed not risk-free (Clark \& Michailova, 2004). For instance, management studies may tackle controversial topics, such as studying relationships between governments and multinational corporations in Communist countries with a centralised regime. Having undertaken our research in a range of such countries, we are also apprehensive that research undertaken by students can place at risk people who facilitate access to participants within the field or translate confidential documents and interview data.

Further, as supervisors, we have been concerned about whether our students are taking the necessary precautions to protect their research participants. de Laine (2000) cautioned that there can be unforeseen effects on participants' privacy when researchers have not adequately anticipated the risk of harming participants. While ethics applications may detail how participants' names should be kept confidential in publications, this does not address issues in developing countries, such as people following researchers or research participants or monitoring phone calls to see who participates in the research. Although securing data and maintaining confidentiality is essential in all contexts, we have found being able to do so is much more problematic in some developing countries. This can be because of high levels of violent crime (meaning stored data, including on computers, can be stolen), political dictatorships/military rule (in which data is checked or confiscated), and poor technology (meaning stored data may be easily intercepted). Moreover, we have noted that working 
through intermediaries requires additional effort to follow ethical protocols. Our students, as research trainees themselves, need guidance to undertake this process.

Many universities keep records of locations and dates when doctoral students are absent from the university, and many countries require travelers to list their travel details on government records. We also suggest our doctoral students have someone to check in with each day so absences can be reported/followed up, and we actively encourage them to contact us regularly, even if they are staying with family/friends during fieldwork. We suggest there could be additional procedures in place to protect doctoral students and their research participants. Certain types of data collection may need to be avoided. For example, we have found undertaking focus groups may not be feasible or appropriate in some locations, given having a group gathered will draw attention to the research and those who participate. Nojonen (2004) referred to needing to interview people in cafes and restaurants located well away from their workplaces and observed that people showed discomfort at notes being taken in public. We have advised our doctoral students that research participants may be protected by meeting in neutral locations, and we have learnt from students about such locations. In some cases, a researcher needs to be careful that recording devices are not visible when interviews are being observed. Moreover, we advise our students to protect participants from distress that may arise if they did reveal more information than they would have liked by contacting them later to have information removed from the research records. Robson (2011) suggested giving interviewees the recorder to hold so they can turn it off when not wanting to continue, conducting interviews in more than one session, and doing a pre-interview to build rapport. The preceding leads us to:

Action guideline 7: Universities should develop guidelines with specific ethical security protocols for doctoral students researching in developing countries to protect them and their research participants. 


\section{Supervisors' inability to influence how doctoral students present research after exiting fieldwork}

We have always felt relieved once our students have returned to the university safely, there have been no complaints to the research ethics office about the data collection, there was no known harm to participants, and all data has been securely stored. However, the research does not stop there - and neither do our ethical challenges. The necessity to exit fieldwork by maintaining relationships with research intermediaries and research participants is well described in the literature (e.g. Binns, 2006; Michailova et al., 2014; Morrison, Gregory \& Thibodeau, 2012; Robson, 2011). Maintaining contact after research projects conclude is an essential aspect of community-engaged research with Indigenous people in developed countries (Bird-Naytowhow, 2017). However, often, research conducted in the developed world involves collecting data and moving on, and research participants rarely expect to hear again from the researchers except perhaps for receiving a summary of research findings. This contrasts with much of the developing world in which building a relationship to conduct research and maintain a relationship post-research is essential.

We have found keeping in contact is often well done by our doctoral students, but sometimes, it also confronts ethical standards. Discussing and presenting the research may have implications for research participants (including those with whom the researcher maintains contact after exiting the field). We have faced ethical challenges when endeavouring to ensure our students maintain confidentiality and anonymity of research participants, which is critical for avoiding damaged relations with organisations and maintaining university reputation. We have limited control over what a student reveals at seminars/conferences or in verbal conversations outside our presence. This is especially so for students who return to remote areas of developing countries where technology limits their contact with us. We surmise some students may think it does not matter if they just verbally reveal participant details, especially 
if providing information in one country and the data was collected in a distant country. However, we know this is problematic given the current availability of publications on the internet and the ability to cross-check against information provided in such publications.

An additional issue relates to publishing by a student after completing their doctorate and about which the supervisor/s has no knowledge. We have worried about whether our students may subsequently publish an article where they inadvertently provide too much detail about their studied organisations. This is not an issue where organisations agreed to be identified in the research or funded the research and this was publicly acknowledged. However, it may reveal individual participants' identity to their managers/members of the public, especially when they were the only manager in a location/workplace. Research participants agree to participate with assurances data will be anonymised, but there may be challenges in keeping anonymity while maximising data usage (see Saunders et al., 2015). Some researchers engage in self-censorship to further protect their participants (and minimise their own risk) (Stringer \& Simmons, 2015). Still, not all doctoral students have sufficient knowledge and experience of how identities may inadvertently be revealed and anonymity compromised. Moreover, such issues may be of greater importance in some developing countries in which revealing identities may place research participants in danger, such as a threat to well-being or imprisonment.

We have explained to students the ethical requirements in publishing and discussing their research. However, we question whether a few years of working with a supervisor/s are sufficient to ensure the student makes the right decisions when they work on their own some years later or when asked, without notice, to provide more insight/information about their doctoral research. Though we accept that, in data collection, some of the approaches we advocate may need to be challenged to be culturally appropriate, there is limited room for negotiation in the dissemination of research findings. Although our students should take 
responsibility at this point of their research experience, we still wonder whether we needed to have done more in establishing expectations. We have had cases where some time after finalising their doctorate, our students contact us to ask about all aspects of the publishing process, including how to ensure confidentiality in published findings, and we have learnt from them about contexts where such confidentiality is not considered by many researchers. We believe advice on disseminating research and publishing extends beyond the supervisors' responsibilities as it can also affect university reputation. We suggest university ethics offices could prepare guidelines specifically for students to follow when publishing their research. This could include a list of questions for students to ask such as: would providing details of the organisation/s studied potentially reveal the organisation/s (and by consequence, the identity of the research participant/s, and in some cases, place participants in danger of arrest/detention), how much demographic data of participants can be included in publications without revealing participants' identity, etc. This justifies:

Action guideline 8: Universities should provide guidelines for doctoral students (during and post studies) about ethically discussing research participants and organisations in publications, presentations and verbal discussions. They should make students aware of the dangers inherent in revealing identities in some developing countries.

\section{Conclusions, limitations, and implications}

In reflecting on our own experiences, we have identified some weaknesses in our practice and position as doctoral supervisors. First, although we tend to take a Research Trainer or Mentor role, rather than having conversations with students about ethics which commence with presenting the university ethics materials and templates, starting a conversation around what ethics means to the student and how they think it should be applied in research. This would place students in a research driver role and allow us to work together with them in establishing 
expectations. Second, we should actively encourage students to challenge us as supervisors in critiquing how research can fit with the enrolling university's ethical protocols while also being culturally appropriate to the fieldwork context. We know ethics committees provide us with opportunities to explain/justify why we find it important to undertake research in particular ways in specific contexts so long as research participants and researchers' safety is ensured. Thus, we can better work with our students to discuss where there can be more negotiation over the practice and move our supervision more into a Knowledge Enthusiast role. In providing our reflection and critiquing our roles, we aim to provide a platform for future research that further examines critical issues and challenges within doctoral supervision.

We acknowledge some limitations of our research. Our discussion focused on doctoral research in business, drawing on our expertise in (international) management, and we expect our insights for supervisors to be relevant across social science research. We note some of the natural sciences may involve more personal, sensitive information being gathered and the insights we have provided may not address additional issues that occur within these disciplines. Moreover, it would be beneficial if future research examined the implementation of some of our action guidelines to examine the impact on fieldwork research practices. While we have adopted a doctoral supervisor perspective, we acknowledge we have not considered doctoral students' perspective. Thus, future research might examine doctoral students' views of ethical issues in the field and how they make choices about their research/data collection when out of contact with supervisors. It would be valuable to examine both student and supervisor perspectives of ethical challenges during students' fieldwork. Such a line of inquiry could directly compare views and experiences through reflective accounts presented in student/supervisor dyads.

The issues we raised have important implications for supervisors of doctoral students conducting fieldwork in developing countries, for doctoral students themselves, and the 
university ethics committees within the universities at which students are enrolled. We expect supervisors who have already worked with doctoral students researching in developing countries will be familiar with some of the ethical challenges we discussed. Some universities may already have in place the procedures we suggested. Simultaneously, supervisors who have not yet supervised students researching in developing countries should gain insight into the ethical issues they may face if they take on such supervision. In many universities in western countries, academics undertake supervisor training modules before commencing or in the initial stages of supervision, and this training includes sessions on research ethics. Additionally, new supervisors are often required to work with experienced supervisors for mentoring purposes, including ethics of research. However, we suggest when students are researching in developing countries, it is crucial one supervisory team member has researched in such a context, if possible. Moreover, supervisors would benefit from ongoing training, including sessions presented by other supervisors/academics about ethical challenges they have experienced when supervising students researching in developing countries.

Our analysis offers doctoral students a greater understanding of the level of commitment and concern of their supervisor/s when the latter guide(s) students through fieldwork in challenging contexts. Such understanding is likely to strengthen the studentsupervisor relationship and help students consider ethical issues in a better-informed manner.

Ethics committees within universities can also gain insights from our analysis. University ethics committees in some western countries have developed specific guidelines for researching Indigenous peoples. Thus, we know the committees understand and are open to making adjustments to reflect specific contexts and research participants. Some of our proposed action guidelines would extend the support ethics committees provide. While we appreciate the need for standardised prescriptive processes, we advise university ethics committees to 
demonstrate greater recognition and appreciation of the ethical issues encountered when doing fieldwork in developing countries.

\section{References}

Agee, J. (2009). Developing qualitative research questions: A reflective process. International Journal of Qualitative Studies in Education, 22(4), 431-447. https://doi.org/10.1080/09518390902736512

Alammar, F.M., Intezari, A., Cardow, A., \& Pauleen, D.J. (2019). Grounded theory in practice: Novice researchers' choice between Straussian and Glaserian, Journal of Management Inquiry, 28(2), 228-245.DOI: 10.1177/1056492618770743

Amerson, R.M., \& Strang, C.W. (2015). Addressing the challenges of conducting research in developing countries. Journal of Nursing Scholarship, 47(6), 584591. https://doi.org/10.1111/jnu.12171

Anteby, M. (2013). Relaxing the taboo on telling our own stories: Upholding professional distance and personal involvement. Organization Science, 24(4), 1277-1290. https://doi.org/10.1287/orsc.1120.0777

Azungah, T. (2019). Challenges in accessing research sites in Ghana: A research note. Qualitative Research in Organizations and Management: An International Journal, 14(4), 410-427. https://doi 10.1108/QROM-07-2018-1671.

Baez, B. (2002). Confidentiality in qualitative research: Reflections on secrets, power and agency. Qualitative Research, 2(1), 36-58.

Bell, K. (2013). Doing qualitative fieldwork in Cuba: Social research in politically sensitive locations. International Journal of Social Research Methodology, 16(2), 109-124. https://doi.org/10.1080/13645579.2011.653217 
Berger, R., Herstein, R., Silbiger, A., \& Barnes, B.A. (2017). Developing international business relationships in a Russian context. Management International Review, 57, 441-471. https://doi.org/10.1007/s11575-016-0295-6

Binns, T. (2006). Doing fieldwork in developing countries: Planning and logistics. In V. Desai \& R. Potter (Eds.), Doing Development Research (pp. 13-24). London: Sage.

Bird-Naytowhow, K., Hatala, A.R., Pearl, T., Judge, A., \& Sjob, E. (2017). Ceremonies of Relationship: Engaging Urban Indigenous Youth in Community-Based Research. International Journal of Qualitative Methods, 16, 1-14. https://doi.org/10.1177/1609406917707899

Bishop R. (2011). Freeing Ourselves from Neo-Colonial Domination in Research. In R. Bishop (Ed.), Freeing Ourselves. Transgressions: Cultural Studies and Education, (pp.1-30). Rotterdam: Sense Publishers.

Cambridge Dictionary (2019). Transition Economy. https://dictionary.cambridge.org/dictionary/english/transition-economy, Accessed $3^{\text {rd }}$ September 2019.

Clark, E. \& Michailova, S. (Eds.), Fieldwork in Transforming Societies. Understanding Methodology from Experience. Houndmills, Palgrave Macmillan.

Crossley, M., \& Vulliamy, G. (1997). Qualitative research in developing countries: Issues and experience, In M. Crossley and G. Vulliamy (Eds.) Qualitative Educational Research in Developing Countries: Current Perspectives, (pp.1-30). Abingdon, UK, Reference Books in International Education.

de Laine, M. (2000). Fieldwork, Participation and Practice. Ethics and Dilemmas in Qualitative Research. London, Sage.

de los Reyes, G., Kim, T. W. \& Weaver, G.R. (2016). Teaching ethics in business schools: A conversation on disciplinary differences, academic provincialism, and the case for 
integrated pedagogy. Academy of Management Learning \& Education, 16(2), 314-336. https://doi.org/10.5465/amle.2014.0402

de Wit-de Vries, E., Dolfsma, W.A., van der Windt, H.J., \& Gerkema, M.P. 2019. Knowledge transfer in university-industry research partnerships: A review. The Journal of Technology Transfer, 44, 1236-1255.

Devereux, S., \& Hoddinott, J. (1992). Introduction, In S. Devereux \& J. Hoddinott (Eds.), Fieldwork in Developing Countries, (pp. xi-xiii), New York, Harvester Wheatsheaf.

Dimov, D., \& Pistrui, J. (2020). Entrepreneurship education as a first-person transformation, Journal of Management Inquiry, https://doi.org/10.1177/1056492620964592

Finlay, L. (2002). 'Outing' the researcher: The provenance, process and practice of reflexivity. Qualitative Health $\quad$ Research, 12(4): 531-545. https://doi.org/10.1177/104973202129120052

Fischer, B.B., Schaeffer, P.R., Vonortas, N.S., \& Queiroz, S. (2018). Quality comes first: university-industry collaboration as a source of academic entrepreneurship in a developing country. Journal of Technology Transfer, 43, 263-284.

George, G., Corbishley, C., Khayesi, J.N.O., Haas, M.R., \& Tihanyi, L. (2016). Bringing Africa in: Promising directions for management research. Academy of Management Journal, 59(2), 377-393. https://doi.org/10.5465/amj.2016.4002

Gokah, G. (2006). The naïve researcher: Doing social research in Africa. International Journal of Social Research Methodology, 9(1), 61-73. https://doi.org/10.1080/13645570500436163

Guillemin, M., \& Gillam, L. (2004). Ethics, reflexivity, and "ethically important moments" in research. Qualitative Inquiry, 10(2), 261-280. https://doi.org/10.1177/1077800403262360 
Hawamdeh S., \& Raigangar, V. (2014). Qualitative interviewing: Methodological challenges in Arab settings. Nurse Researcher, 21(3), 27-31. https:// doi: $10.7748 / \mathrm{nr} 2014.01 .21 .3 .27 . e 357$

Hawkins, J.S. \& Emanuel, E.J. (2008). Introduction: Why exploitation, In J.S. Hawkins and E.J. Emanuel (Eds.), Exploitation and Developing Countries: The Ethics of Clinical Research, Princeton, Princeton University Press.

Hellawell, D. (2006). Inside-out: Analysis of the insider-outsider concept as a heuristic device to develop reflexivity in students doing qualitative research. Teaching in Higher Education, 11(4), 483-494. https://doi.org/10.1080/13562510600874292

Hoskisson, R.E., Eden, L., Lau, C.M., \& Wright, M. (2000). Strategy in emerging countries. Academy of Management Journal, 43(3), 249-267. https://doi.org/10.5465/1556394

Howes, A., Grimes, P., Lopez, A.L., Esteban, P.G., Shohel, M.M.C., Neff, D., \& Ramsden, A. (2006). PhD fieldwork in developing countries: The issue of time, Presented at the British Association for International \& Comparative Education (BAICE) Conference. https://addi.ehu.es/handle/10810/26409?show=full, Accessed 6th September 2019.

Hutchings, K., \& Michailova, S. (2006). The impact of group membership on knowledge sharing in Russia and China. International Journal of Emerging Markets, 1(1), 21-34. https://doi.org/10.1108/17468800610644988

Jackson, T. (2013). Reconstructing the indigenous in African management research. Management International Review, 53(1), 13-38. https://doi.org/10.1007/s11575-0120161-0

Jentsch, B., \& Pilley, C. (2003). Research relationships between the South and the North: Cinderella and the ugly sisters?. Social Science and Medicine, 57, 1957-1967. https://doi.org/10.1016/S0277-9536(03)00060-1 
Lages, C.R., Pfajfar, G., \& Shoham, A. (2015). Challenges in conducting and publishing research on the Middle East and Africa in leading journals. International Marketing Review, 32(1), 52-77. DOI 10.1108/IMR-12-2014-0374

Liong, M. (2015). In the shadows of deception. Qualitative Research Journal, 15(1), 61-73. DOI 10.1108/QRJ-03-2014-0008

Litewka, S.G. (2011). The challenges of conducting research in developing countries, Conversations with Sergio Litewka, MD, MPH. Paper 1 Human Research Protection Office. http://digitalcommons.wustl.edu/hrpoconf_litewka2011/1, Accessed $6^{\text {th }}$ September 2019.

Meyer, K.E., \& Peng, M.W. (2018). Theoretical foundations of emerging economy business research. Journal of International Business Studies, 47(1), 3-22. https://doi.org/10.1057/jibs.2015.34

Michailova, S. (2004). Contextualising fieldwork: Reflections on conducting research in Central Europe, In R. Marschan-Piekkari \& C. Welch (Eds.), Handbook of Qualitative Research Methods for International Business, (pp. 365-383), Cheltenham, Edward Elgar.

Michailova, S., Piekkari, R., Plakoyiannaki, E., Ritvala, T., Mihailova, I., \& Salmi, A. (2014). Breaking the silence about exiting fieldwork: A relational approach and its implications for theorizing. Academy of Management Review, 39(2), 138-161. https://doi.org/10.5465/amr.2011.0403

Michailova, S., \& Worm, V. (2003). Personal networking in Russia and China: Blat and Guanxi. European Management Journal, 21(4), 509-519. https://doi.org/10.1016/S0263-2373(03)00077-X 
Mokgatla, B., IJsselmuiden, C., Wassenaar, D., \& Kasule, M. (2018). Mapping research ethics committees in Africa: Evidence of the growth of ethics review of health research in Africa. Developing World Bioethics, 18, 341-348. https://doi.org/10.1111/dewb.12146 Morrison, Z.J., Gregory, D. \& Thibodeau, S. (2012). 'Thanks for using me’: An exploration of exit strategy in qualitative research. International Journal of Qualitative Methods, 11(4), 416-427. https://doi.org/10.1177/160940691201100408

Mortari, L. (2015). Reflectivity in Research Practice: An Overview of Different Perspectives. International Journal of Qualitative Methods, 14(5), 1-9.

Nguitragool P. (2014.) Learning from locals: Doing interviews in Southeast Asia, In M. Huotari, J. Rüland, \& J. Schlehe (Eds.) Methodology and Research Practice in Southeast Asian Studies, (18-143), London, Palgrave Macmillan.

Nhung, T., Hendy, M., Basuray, T., \& Smith, W.P. (2017). Teaching a business ethics course using team debates. Journal of Business Ethics Education, 14, 5-22. DOI: $10.5840 /$ jbee2017142

Nojonen, M. (2004). Fieldwork in a low-trust (post) communist society, In E. Clark \& S. Michailova (Eds.), Fieldwork in Transforming Societies. Understanding Methodology from Experience, (pp. 157-176), Houndmills, Palgrave Macmillan.

Peng, M., \& Luo, Y. (2000). Managerial ties and firm performance in a transitional economy: The nature of a micro-macro link. Academy of Management Journal, 43(3), 486-501. https://doi.org/10.5465/1556406

Robinson, N. (2018). Australia hosting unprecedented numbers of international students. ABC News Online., https://www.abc.net.au/news/2018-04-18/australia-hostingunprecedented-numbers-international-students/9669030, Accessed 3rd September 2019. 
Robson, E. (2011). Interviews worth the tears? Exploring dilemmas of research with young carers in Zimbabwe. Ethics, Place \& Environment, 4(2), 135-142. https://doi.org/10.1080/713665943

Sabati, S. (2019). Upholding "colonial unknowing” through the IRB: Reframing institutional research ethics. Qualitative Inquiry, 25(9-10), 1056-1064. https://doi.org/10.1177/1077800418787214

Sampson, H., \& Thomas, M. (2003). Risk and responsibility. Qualitative Research, 3(2), 16589. https://doi.org/10.1177/14687941030032002

Saunders, B., Kitzinger, J., \& Kitzinger, C. (2015). Anonymising interview data: Challenges and compromise in practice. Qualitative Research, 15(5), 616-632. https://doi.org/10.1177/1468794114550439

Shapira-Lishchinsky, O. (2011). Teachers' critical incidents: Ethical dilemmas in teaching practice. Teaching and Teacher Education, 27, 648-656.

Smith, L.T. (2013). Decolonising Methodologies: Research and Indigenous Peoples, $2^{\text {nd }}$ edn., London: Zed Books.

Smith, J. (2016). Reflections on teaching research ethics in education for international postgraduate students in the UK. Teaching in Higher Education, 21(1), 94-105. https://doi.org/10.1080/13562517.2015.1115968

Stening, B. W., \& Skubik, D. W. (2007). Do management and international business researchers need a code of ethics? Management International Review, 47(1), 103-126. https://doi.org/10.1007/s11575-007-0006-4

Stringer, C., \& Simmons, G. (2015). Stepping through the looking glass: Researching slavery in New Zealand's fishing industry. Journal of Management Inquiry, 24(3), 253-263. https://doi.org/10.1177/1056492614561228 
Waibel, G., \& Ehlert, J. (2012). Fuzzy Reality. https://www.dandc.eu/en/article/socialscience-research-challenging-important-vietnam, Accessed 26th October 2020.

Wallace, M., \& Sheldon, N. (2015). Business research ethics: Participant observer perspectives. Journal of Business Ethics, 128, 267-277. https://doi.org/10.1007/s10551-014-2102-2

Widdows, H. (2007). Is global ethics moral neo-liberalism? An investigation of the issue in the context of bioethics. Bioethics, 21(6), 305-315.

World Health Organization (WHO) (2009). Research ethics committees. Basic concepts for capacity-building, https://www.who.int/ethics/Ethics_basic_concepts_ENG.pdf, Accessed $21^{\text {st }}$ February 2021.

World Population Review (2019). Developing Countries 2019.

http://worldpopulationreview.com/countries/developing-countries/, Accessed $3^{\text {rd }}$ September 2019.

World Population Review. (2021). Western Countries 2021, https://worldpopulationreview.com/country-rankings/western-countries, Accessed $21^{\text {st }}$ February 2021.

Wright, A.L, Middleton, S., Hibbert, P., \& Brazil, V. (2020). Getting on with field research using participant deconstruction, Organization Research Methods, DOI: $10.1177 / 1094428118782589$

Wright, A., Murray, J.P., \& Geale, P. (2007). A phenomenographic study of what it means to supervise doctoral students, Academy of Management Learning and Education, 6(4), 458-474. https://doi.org/10.5465/amle.2007.27694946 
Table 1: Ethical issues arising from challenges in researching in developing countries

\begin{tabular}{|c|c|}
\hline $\begin{array}{c}\text { Developing countries' research } \\
\text { environment }\end{array}$ & Ethical issues for researchers \\
\hline \multirow[t]{3}{*}{ No or little tradition of research } & Government can prevent/restrict research; researchers cannot always decide who/what they can research \\
\hline & $\begin{array}{l}\text { Organisations are sceptical of researchers' motives; researchers need to consider carefully how to recruit } \\
\text { and engage with research participants }\end{array}$ \\
\hline & $\begin{array}{l}\text { Organisations/research participants are often unfamiliar with research practices; researchers need to decide } \\
\text { how much they need to explain the research process }\end{array}$ \\
\hline \multirow[t]{2}{*}{$\begin{array}{l}\text { No or little understanding of } \\
\text { ethics approval processes }\end{array}$} & $\begin{array}{l}\text { Research participants distrust researchers' assurances of confidentiality i.e. believe researchers will report } \\
\text { their responses to managers, government or others in authority; researchers need to consider the extent to } \\
\text { which they 'convince' people to participate }\end{array}$ \\
\hline & $\begin{array}{l}\text { Gatekeepers (officials, secretaries) block access to data collection fearing disclosure of information; } \\
\text { researchers need to consider alternative ethical approaches to accessing participants }\end{array}$ \\
\hline $\begin{array}{l}\text { Lack of reliable, publicly- } \\
\text { available databases of } \\
\text { organisations/contact details }\end{array}$ & $\begin{array}{l}\text { Researchers need to develop networks and work through intermediaries to gain access to } \\
\text { organisations/participants without compromising ethics standards they have committed to via their ethics } \\
\text { approval applications }\end{array}$ \\
\hline \multirow[t]{2}{*}{$\begin{array}{l}\text { Research participants will provide } \\
\text { socially-desirable responses }\end{array}$} & $\begin{array}{l}\text { Survey or interview responses may not fully address research questions; researchers need to consider } \\
\text { responsibility to include such data }\end{array}$ \\
\hline & $\begin{array}{l}\text { Research participants provide a response to all questions including those with which they may not be } \\
\text { comfortable; researchers need to ethically question which data to include }\end{array}$ \\
\hline $\begin{array}{l}\text { Research participants often prefer } \\
\text { not to be recorded }\end{array}$ & $\begin{array}{l}\text { Researchers may not capture a full record of interview data, and need to make ethical decisions about how } \\
\text { they elaborate on notes taken during interviews }\end{array}$ \\
\hline \multirow[t]{2}{*}{$\begin{array}{l}\text { Research participants are } \\
\text { generally distrustful of } \\
\text { researchers they do not know }\end{array}$} & $\begin{array}{l}\text { Researchers need to devote considerable time to build a relationship with research participants prior to } \\
\text { data collection and maintain the relationship after data collection, and need to ethically question how they } \\
\text { maintain objectivity in the research }\end{array}$ \\
\hline & $\begin{array}{l}\text { Researchers may feel an ethical obligation not to report (some) information where they have developed a } \\
\text { friendship with research participants }\end{array}$ \\
\hline
\end{tabular}




\begin{tabular}{|l|l|}
\hline $\begin{array}{l}\text { Research consent does not follow } \\
\text { western countries' practices }\end{array}$ & $\begin{array}{l}\text { Researchers may need to adapt their ethics protocols to have consent provided by others associated with } \\
\text { the research participant }\end{array}$ \\
\cline { 2 - 2 } & $\begin{array}{l}\text { Researchers may need to accept verbal, rather than written consent and consider how to ethically retain } \\
\text { such consent }\end{array}$ \\
\cline { 2 - 2 } & $\begin{array}{l}\text { Research participants may consent out of obligation to managers; researchers need to make ethical } \\
\text { decisions about inclusion of such data }\end{array}$ \\
\hline $\begin{array}{l}\text { Research participants expect } \\
\text { reciprocity for involvement in } \\
\text { research }\end{array}$ & $\begin{array}{l}\text { Researchers need to provide gifts of appreciation of research participants' time within constraints of their } \\
\text { own ethics protocols }\end{array}$ \\
\hline Risks in research environment & $\begin{array}{l}\text { Researcher physical safety and risks entailed in following ethical practices to protect research data may } \\
\text { result from limited communications and infrastructure (particularly in remote or rural areas) }\end{array}$ \\
\cline { 2 - 2 } & $\begin{array}{l}\text { Researchers may avoid sensitive research topics or self-censor information to fit with a climate in which } \\
\text { they may be at physical risk due to lack of protections for researchers }\end{array}$ \\
\hline
\end{tabular}




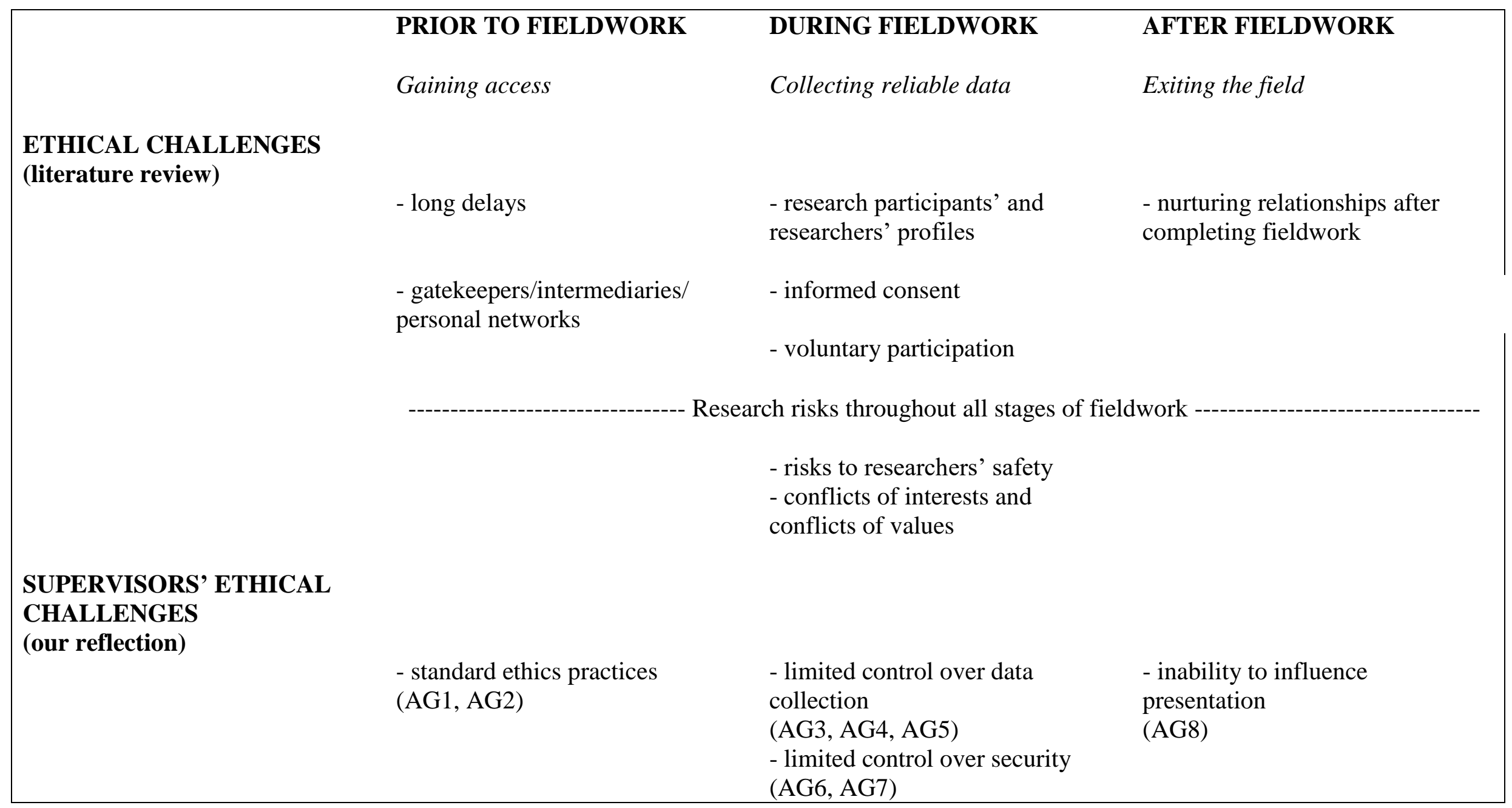

Figure 1: Ethical challenges for supervisors of business doctoral students researching in developing countries Note: $\mathrm{AG}=$ action guideline e.g. AG1 is Action Guideline 1 
